Elsevier

HEARES 01247

\title{
Cochlear blood flow autoregulation in Wistar-Kyoto rats
}

\author{
W.S. Quirk ${ }^{1}$, H.A. Dengerink ${ }^{2}$, J.K. Coleman ${ }^{2}$ and J.W. Wright ${ }^{2}$ \\ 'Kresge Hearing Research Institute, The University of Michigan, Ann Arbor, Michigan, U.S.A. and \\ ${ }^{2}$ Department of Psychology, Washington State University, Pullman, Washington, U.S.A.
}

(Received 13 December 1988; accepted 2 May 1989)

\begin{abstract}
Wistar-Kyoto rats (WKY) were intra-arterially infused with angiotensin II (AII) or phenylephrine for 10 min. Both vasoactive compounds produced an initial increase in cochlear blood flow (CoBF) as measured by laser Doppler flowmetry, followed by a slow steady return to baseline, despite sustained elevations in systemic blood pressure. These results suggest autoregulation of CoBF in the WKY rat. In a second experiment, AII was infused directly into the anterior inferior cerebellar artery (AICA) which feeds the cochlear artery. Significant reductions in $\mathrm{CoBF}$ were noted without changes in systemic blood pressure. Pretreatment with the specific angiotensin-receptor antagonist, sarthran ( $\mathrm{Sar}^{1}, \mathrm{Thr}^{8}-\mathrm{AII}$ ), diminished subsequent All-induced reductions in CoBF. These results indicate that AII binding to vascular receptors may induce vasoconstriction in the supplying vessels of the cochlea, and thus, the interaction of blood-borne AII and vascular angiotensin receptors may participate in the autoregulation of CoBF.
\end{abstract}

Autoregulation; Cochlear blood flow; Laser Doppler flowmeter; Wistar-Kyoto rat; Angiotensin II; Phenylephrine

\section{Introduction}

Previous research has demonstrated that cochlear blood flow (CoBF) can be driven by changes in systemic blood pressure (Goodwin et al., 1984; Miller et al., 1983, 1984; Snow and Suga, 1972; Suga and Snow, 1969; Wright et al., 1985a). For example, increases in CoBF occur with elevated blood pressure in response to epinephrine and ephedrine (Snow and Suga, 1972), angiotensin II (Goodwin et al., 1984; Quirk et al., 1988; Snow and Suga, 1972), nicotine (Dengerink et al., 1985; Laugel et al., 1988), phenylephrine (Laugel et al., 1988; Sillman et al., 1988), and methoxamine (Miller et al., 1984). There are also indications that CoBF may be subject to local autoregulation (Dengerink et al., 1985; Goodwin et al., 1984; Hultcrantz et al., 1982; Miller and Dengerink, 1988; Miller et al., 1984; Quirk et al., 1988).

Correspondence to: Wayne S. Quirk, Kresge Hearing Research Institute, The University of Michigan, 1301 East Ann Street, Ann Arbor, MI 48109-0506, U.S.A.
Classically, autoregulation is defined as the ability of a tissue to maintain relatively constant flow despite variations in perfusion pressure (Bayliss, 1902). Autoregulation of the cerebral vessels has been well documented in normotensive (Coyle and Heistad, 1986) and spontaneously hypertensive rats (Baumbach and Heistad, 1985; Harper and Bohlen, 1981; Sadoshima et al., 1985), cats (Chang et al., 1985), newborn canines (Pasternak and Groothius, 1985) and baboons (Strandgaard et al., 1975).

Since several authors have proposed that CoBF may be closely related to cerebral blood flow (Lawrence et al., 1977; Miller et al., 1983), evidence of cochlear blood flow autoregulation should not be a surprising discovery. Indeed, autoregulation of CoBF has been demonstrated during large deviations in blood pressure (Flynn et al., 1988; LaRouere et al., 1988; Quirk et al., 1988). In one case, positive end expiratory pressure (PEEP) induced large decreases in blood pressure in guinea pigs that resulted in initial decreases in CoBF, followed by a slow, steady increase in CoBF toward baseline measures (LaRouere et al., 1988). In another example, intra cerebroventricular infu- 
sions of angiotensin II (AII) in guinea pigs induced sustained elevations in blood pressure and transient increases of $\mathrm{CoBF}$, followed by declines in CoBF (Flynn et al., 1988). Similarly, intraarterial infusion of several doses of angiotensin II (AII) $(10,100$ and $1000 \mathrm{pmol})$ induced large, sustained elevations of systemic blood pressure in spontaneously hypertensive rats (SHRs) accompanied by initial increases in $\mathrm{CoBF}$, and subsequent slow, steady recoveries of CoBF. (Quirk et al., 1988). In the same study, AII-induced increases in systemic blood pressure in normotensive WistarKyoto (WKY) rats were generally followed by sustained increases in CoBF. However, infusion of the high dose of AII (1000 pmol) resulted in similar increases in systemic blood pressure and CoBF, but during the final minute of the 5 -min infusion period CoBF decreased sharply.

In the present study, we extended the intraarterial infusion period from $5-10 \mathrm{~min}$ to provide ample time for CoBF autoregulation to occur in the WKY rat. Phenylephrine was also infused for $10 \mathrm{~min}$ to test the effect of another vasoactive compound on autoregulation. To determine the possible contribution of vascular AII receptors to CoBF autoregulation by vasoconstriction of the cochlea's supplying vessels, AII was infused into the artery supplying the cochlear artery and changes in blood pressure and CoBF were measured. Another group of animals were pretreated with a specific, AII-receptor antagonist to test for possible disruption of the AII-induced vasoconstriction.

\section{Method}

\section{Subjects}

Mature, male Wistar-Kyoto rats derived from stock obtained from Taconic Farms were maintained at $21-22^{\circ} \mathrm{C}$ in group cages under a $12: 12$ hour light:dark cycle initiated at 07:00 h. Food and water were available ad libitum.

\section{Experiment 1: Intra-arterial infusion of AII and phenylephrine}

\section{Preparations}

Each animal was anesthetized with Ketaset (Bristol-Myers, Inc.) and Rompun (Haver, Inc.)

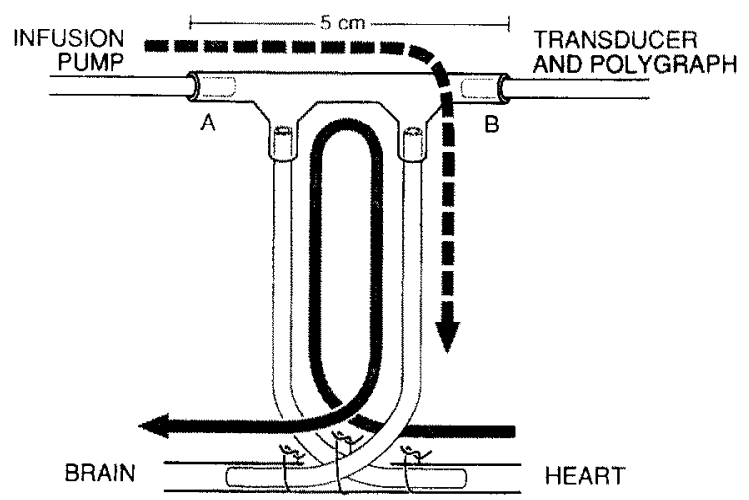

Fig. 1. Diagram of the flow-through catheter. The catheter is constructed from a glass blown double t-junction and PE 60 tubing (Clay Adams) and is inserted into the carotid artery as shown. Blood flow is denoted by solid arrows and infusion flow by dashed arrows.

(100 and $2 \mathrm{mg} / \mathrm{ml}$ respectively; $1 \mathrm{ml} / \mathrm{kg} \mathrm{i} . \mathrm{m}$.). Body temperature was monitored with a rectal probe and maintained at $38 \pm 1^{\circ} \mathrm{C}$ with heating pads. A flow-through catheter designed to allow infusion and continuous recording of blood pressure (Fig. 1) was inserted into the right carotid artery. The catheter was constructed of PE-60 (Clay Adams) tubing, a hand-blown glass double $\mathrm{t}$-junction and two $3 \mathrm{ml}$ syringes. Approximately 2 $\mathrm{cm}$ of the carotid artery was exposed and both distal and proximal points of the exposure were retracted. Two $8 \mathrm{~cm}$ lengths of PE-60 tubing were connected to the double t-junction, filled with heparinized saline $(75 \mathrm{U} / \mathrm{ml} 0.15 \mathrm{M} \mathrm{NaCl})$, crossed and inserted into separate cuts made in the retracted portions of the artery and sutured in place. An additional suture was tied at the crossing point of the PE- 60 tubing to prevent distortion of the artery and to further secure the catheter. Blood was allowed to flow through the catheter loop replacing the $0.3 \mathrm{ml}$ of heparinized saline. Preliminary testing showed that the addition of this amount of saline to the systemic circulation did not alter blood pressure or CoBF baselines. Additionally, treatment of the glass $t$-junctions with sigma coate (SL-2, Sigma Chemical Co.) and the polyethelene tubing with tomac heparin complex (2\%: Polysciences, Inc.) reduced and in most cases eliminated any build up of platelets in the catheter system. The end of the t-junction marked ' $A$ ' in Fig. 1, was in line with the infusion pump (Razel, 
Model A-99) allowing the solution to merge with the flow of blood. The other end of the catheter (Fig. 1, 'B') was connected to a Statham transducer (Model P23AC) and a Grass Instruments polygraph (model 7B) for measurement of blood pressure.

The animal's head was secured in a head holder and the right bulla was exposed and opened for access to the cochlea according to the procedure described by Miller et al. (1983). The laser Doppler probe (Optokinetics Corp., Advanced Model 2100 ) was placed on the basal turn of the cochlea. Baseline measures were obtained for both blood pressure and CoBF.

\section{Protocol}

One group of 8 WKY animals was infused for $10 \mathrm{~min}$ with $1000 \mathrm{pmol} / \mathrm{kg} / \mathrm{min}$ of AII (U.S. Biochemical) in sterile $0.15 \mathrm{M} \mathrm{NaCl}$ at a rate of 50 $\mu 1 / \mathrm{min}$. A second group of 8 animals was treated equivalently, however, phenylephrine $(0.02$ $\mathrm{mg} / \mathrm{kg} / \mathrm{min}$ in sterile $0.15 \mathrm{M} \mathrm{NaCl}$ at $50 \mu \mathrm{l} / \mathrm{min}$ ) was substituted for AlI. A final group of 8 control animals was infused with $0.15 \mathrm{M} \mathrm{NaCl}$ at a rate of $50 \mu \mathrm{l} / \mathrm{min}$. Blood pressure and CoBF were monitared throughout the infusion period and for a 15-min recovery period.

\section{Statistical analysis}

Baseline blood pressures were analyzed using a one-way analysis of variance (ANOVA). Absolute $\mathrm{mm} \mathrm{Hg}$ changes in blood pressure from baseline were converted to percentages to allow differences between blood pressure and CoBF to be analyzed with a one-way repeated measures ANOVA.

\section{Experiment 2: Anterior inferior cerebellar artery (AICA) infusion of AII}

\section{Preparations}

Each animal was anesthetized as previously described and the right carotid artery was catheterized using PE-50 tubing as described by Wright et al. (1985b) for blood pressure measurement. The right bulla was exposed and opened for access to the cochlea according to the procedure described by Miller et al. (1983) and the tissues posterior and medial to the bulla were dissected to allow access to the AICA. The laser Doppler flowmeter probe was placed on the basal turn of the cochlea. Baseline measures were obtained for both blood pressure and CoBF.

Infusion into the AICA was accomplished with an insulin pump (Travenol Laboratories, Model AS6MP) calibrated to deliver $100 \mathrm{nl} / \mathrm{min}$ through a $1 \mathrm{ml}$ syringe. One end of a $20 \mathrm{~cm}$ length of PE-10 tubing was secured to the syringe via a 30 ga syringe needle and the other end was inserted into the blunt end of a glass micropipette. The tip of the pipette was pulled to an external diameter of approximately $15 \mu \mathrm{m}$. The infusion catheter line was loaded with peptide and $0.5 \%$ Evans blue dye in distilled water, separated by $100 \mathrm{nl}$ of air. The micropipette tip penetrated to a depth of approximately $2 \mu \mathrm{m}$ and was inserted such that it ran parallel with the vessel, thereby minimizing obstruction of blood flow.

\section{Protocol}

One group of 11 animals was infused with 0.15 $\mathrm{M} \mathrm{NaCl}$ for $10 \mathrm{~min}$. Two additional groups of 11 animals were infused with AII (10 or 100 $\mathrm{pmol} / 100 \mathrm{nl}$ in $0.15 \mathrm{M} \mathrm{NaCl}$ ) at a rate of 100 $\mathrm{nl} / \mathrm{min}$ for $10 \mathrm{~min}$. A final group of animals was infused with a pretreatment of sarthran (50 $\mathrm{nmol} / 100 \mathrm{nl}$ in $0.15 \mathrm{M} \mathrm{NaCl})$ or vehicle $(0.15 \mathrm{M}$ $\mathrm{NaCl}$ ) at a rate of $100 \mathrm{nl} / \mathrm{min}$ for $10 \mathrm{~min}$, followed 5 min later with AII $(100 \mathrm{pmol} / 100 \mathrm{nl} 0.15$ $\mathrm{M} \mathrm{NaCl}$ ) at a rate of $100 \mathrm{nl} / \mathrm{min}$ for $10 \mathrm{~min}$. Blood pressure and CoBF were monitored throughout the infusion period and for a 15-min recovery period.

\section{Statistical analysis}

Baseline blood pressures were analyzed using a one-way analysis of variance. Absolute changes in blood pressure and percentage changes in CoBF from baseline were analyzed using a repeated measures one-way analysis of variance (ANOVA).

\section{Results}

Experiment 1: Intra-arterial infusion of $A I I$ and phenylephrine

There was no significant difference in the baseline blood pressure between groups as established during the $10 \mathrm{~min}$ period prior to infusion. The mean haseline blood pressure and SEM for each 

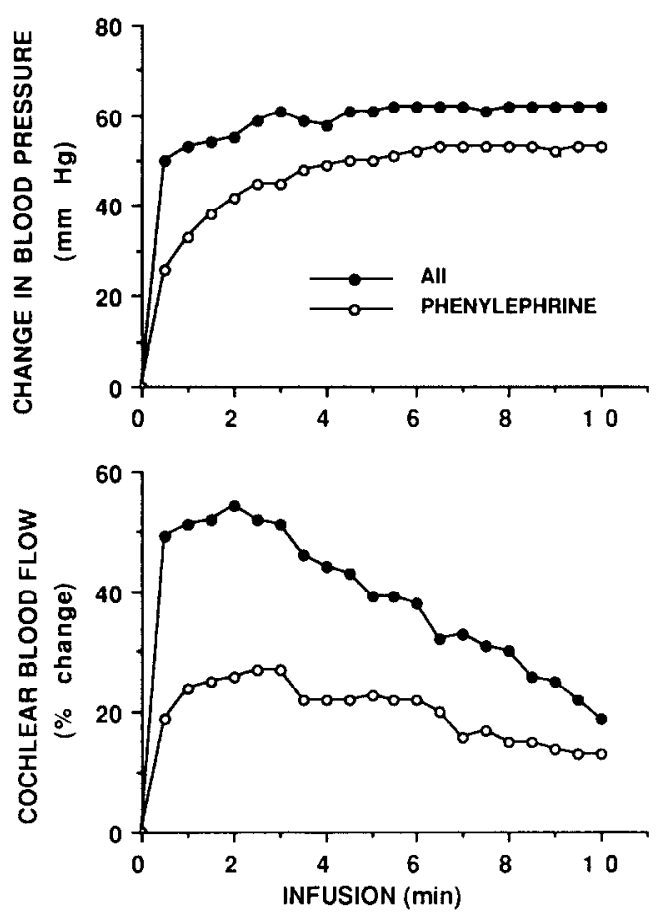

Fig. 2. Mean changes in blood pressure and cochlear blood flow in Wistar-Kyoto rats in response to 10-min intra-arterial infusion of AII $(1000 \mathrm{pmol} / \mathrm{kg} / \mathrm{min}$ in $0.15 \mathrm{M} \mathrm{NaCl}$ at 50 $\mu \mathrm{l} / \mathrm{min})$ and phenylephrine $(0.02 \mathrm{mg} / \mathrm{kg} / \mathrm{min}$ in $0.15 \mathrm{M} \mathrm{NaCl}$ at $50 \mu \mathrm{l} / \mathrm{min}$ ).

group was $83.1 \pm 2.8 \mathrm{~mm} \mathrm{Hg}, 86.7 \pm 2.3 \mathrm{~mm} \mathrm{Hg}$ and $85.9 \pm 3.7 \mathrm{~mm} \mathrm{Hg}$ (AII, phenylephrine and $0.15 \mathrm{M} \mathrm{NaCl}$, respectively). Infusion of $0.15 \mathrm{M}$ $\mathrm{NaCl}$ did not induce any changes in blood pressure or CoBF as has previously been demonstrated (Quirk et al., 1988). Infusion of $1000 \mathrm{pmol}$ of AII resulted in a mean \pm SEM blood pressure increase of $59.5 \pm 4.6 \mathrm{~mm} \mathrm{Hg}$, followed by a plateau at approximately $60 \mathrm{~mm} \mathrm{Hg}$ above baseline (Fig. 2, A). CoBF showed an initial increase for the first $4 \mathrm{~min}$ of AII infusion reaching a mean \pm SEM of $50.2 \pm 2.3 \%$ above baseline followed by a slow, steady decline toward baseline throughout the remainder of the infusion period (Fig. 2, B). When blood pressure data were converted from absolute $\mathrm{mm} \mathrm{Hg}$ to percent changes, there was a significant difference between AII-induced changes in systemic blood pressure and CoBF over time $(\mathrm{F}=10.22$, df $=1,14, P<0.01)$. In summary, blood pressure remained elevated throughout the infusion period while CoBF showed an initial increase followed by a slow decrease toward baseline measures.

Infusion of phenylephrine was characterized by a slow consistent increase in blood pressure throughout the infusion period to a maximum increase of $53 \pm 6.3 \mathrm{~mm} \mathrm{Hg}$ above baseline at the $10 \mathrm{~min}$ time point (Fig. 2, A). However, CoBF showed an initial $27 \pm 4.1 \%$ increase by minute 3 of the phenylephrine infusion followed by a decrease and plateau at approximately $21 \pm 3.7 \%$ for the next $4 \mathrm{~min}$ of the $10-\mathrm{min}$ infusion period. The final 3 min of the infusion was characterized by a steady decline to $13 \pm 5.7 \%$ above baseline by the end of the infusion period (Fig. 2, B). When blood pressure data were converted from absolute change in $\mathrm{mm} \mathrm{Hg}$ to percent changes, there was a significant difference between blood pressure and CoBF changes over time with the 10 -min phenylephrine infusion $(\mathrm{F}=16.53, \mathrm{df}=1,14, \quad P<0.001)$. In summary, CoBF slowly returned to baseline following an initial increase while blood pressure increased and remained elevated throughout the infusion period.

\section{Experiment 2: AICA infusion of $A I I$}

There was no significant difference in the baseline blood pressure between groups as established during the $10 \mathrm{~min}$ prior to infusion. The mean baseline blood pressure for all groups was $84.2 \pm$ $3.5 \mathrm{~mm} \mathrm{Hg}$. There was no change in systemic blood pressure in response to AICA infusions of $0.15 \mathrm{M} \mathrm{NaCl}$ or AII (10 or $100 / \mathrm{pmol} / \mathrm{min}$; Fig. 3 . A). However, there was a significant change in CoBF among groups during the infusions of 0.15 $\mathrm{M} \mathrm{NaCl}, 10$ and $100 \mathrm{pmol} / \mathrm{min}$ of AII $(\mathrm{F}=29.67$. $\mathrm{df}=2,30, P<0.001$ ). Infusion of $0.15 \mathrm{M} \mathrm{NaCl}$ did not change CoBF (Fig. 3, B), however, infusion of $10 \mathrm{pmol} / \mathrm{min}$ AII resulted in a steady decrease (mean $=-6.8 \pm 0.9 \%$ ) in CoBF during the 10-min infusion period that was significantly different from $0.15 \mathrm{M} \mathrm{NaCl}$ infusion $(\mathrm{F}=21.28$, $\mathrm{df}=1,20, P<0.001$; Fig. 3, B ). Infusion of 100 $\mathrm{pmol} / \mathrm{min}$ AII (Fig. 3, B) also decreased CoBF (mean $=-14.8 \pm 1.2 \%$ ) during the infusion period and was significantly different than both $0.15 \mathrm{M}$ $\mathrm{NaCl}-(\mathrm{F}=47.31, \mathrm{df}=1,20, \quad P<0.001)$ and 10 $\mathrm{pmol} / \mathrm{min}$ AII-induced changes in $\operatorname{CoBF}(\mathrm{F}=$ 14.59, $\mathrm{df}=1,20, \quad P<0.001)$. 
There was no change in systemic blood pressure in response to $100 \mathrm{pmol} / \mathrm{min}$ AII infusion in animals pretreated with sarthran or $0.15 \mathrm{M} \mathrm{NaCl}$ (Fig. 4, A). Animals pretreated with $0.15 \mathrm{M} \mathrm{NaCl}$ and infused with AII ( $100 \mathrm{pmol} / \mathrm{min})$ resulted in a persistent decrease in $\mathrm{CoBF}$ (mean $=-7.6 \pm$ $1.0 \%$ ) during the 10 -min period. However, sarthran pretreatment diminished AII-induced decreases in $\mathrm{CoBF}$ (Fig. 4, B). A significantly ( $\mathrm{F}=$ 14.17, $\mathrm{df}=1,6, P<0.01$ ) greater decrease in CoBF was observed in animals pretreated with $0.15 \mathrm{M}$ $\mathrm{NaCl}$ (mean $=-7.6 \pm 1.0 \%$ ) than in animals pretreated with sarthran (mean $=-0.6 \pm 0.5 \%)$ in response to AII infusion.

\section{Discussion}

The interpretation that $\mathrm{CoBF}$ is subject to autoregulation has received support in recent studies (Dengerink et al., 1985; Flynn et al., 1988; Hultcrantz et al., 1982; LaRouere et al., 1988; Miller et al., 1983, 1984; Quirk et al., 1988). Since
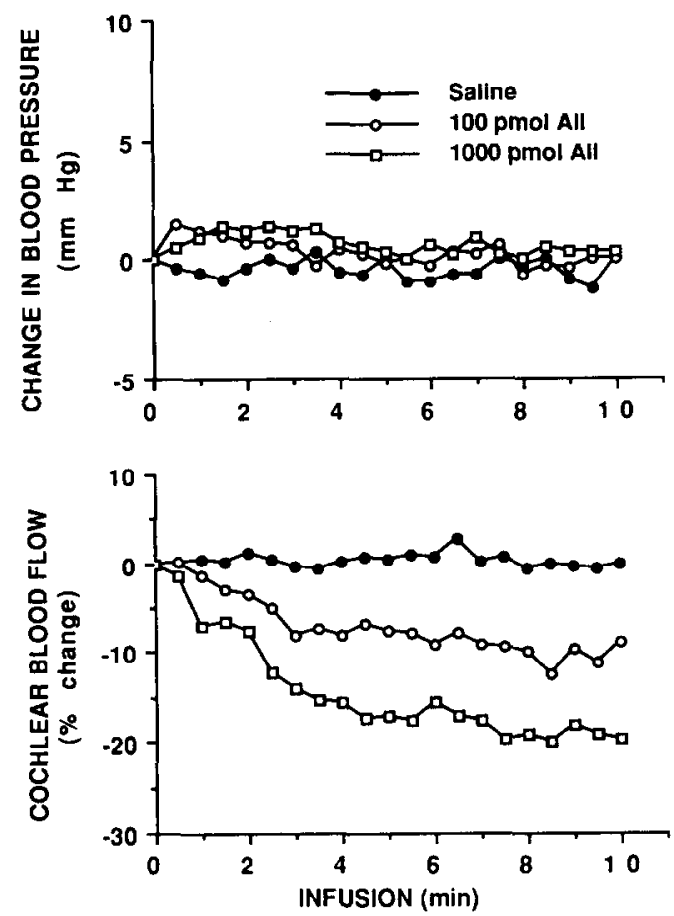

Fig. 3. Mean changes in blood pressure and cochlear blood flow in Wistar-Kyoto rats during anterior inferior cerebellar (AICA) infusions of $0.15 \mathrm{M} \mathrm{NaCl}, 10$ and $100 \mathrm{pmol} / 100 \mathrm{nl}$ $0.15 \mathrm{M} \mathrm{NaCl}$ at $100 \mathrm{nl} / \mathrm{min}$ for $10 \mathrm{~min}$ of angiotensin II.
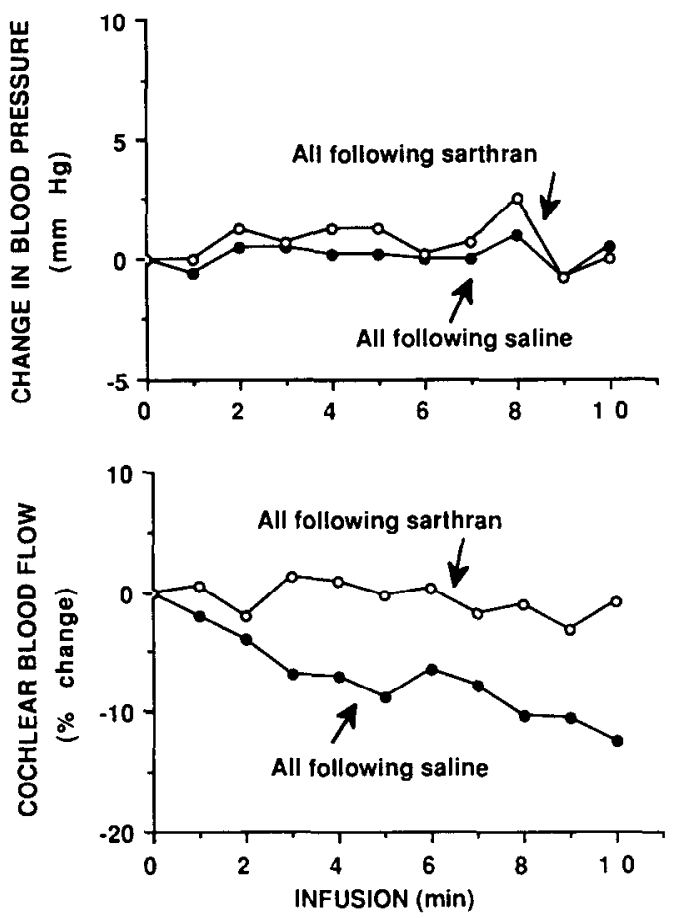

Fig. 4. Mean changes in blood pressure and cochlear blood flow in Wistar-Kyoto rats following pretreatment with $0.15 \mathrm{M}$ $\mathrm{NaCl}$ or sarthran (50 nmol in $2 \mu 10.15 \mathrm{M} \mathrm{NaCl}$ at $1 \mathrm{nmol} / \mathrm{min}$ ) during anterior inferior cerebellar artery infusion of 100 $\mathrm{pmol} / 100 \mathrm{nl}$ in $0.15 \mathrm{M} \mathrm{NaCl}$ at $100 \mathrm{nl} / \mathrm{min}$ ) of angiotensin II.

cochlear blood flow has been proposed to be similar to cerebral blood flow (Lawrence et al., 1977; Miller et al., 1983), then the well-documented autoregulation of cerebral vessels (e.g. Baumbach and Heistad, 1985) supports the probability that $\mathrm{CoBF}$ may be autoregulated as well. The current study addressed the issue of whether CoBF in WKY rats is subject to autoregulation during sustained elevations in blood pressure. A previous investigation demonstrated a pattern of CoBF changes that could be interpreted as a form of autoregulation in the later stages of a 5 -min controlled infusion of AII (1000 pmol/ $\mathrm{kg}$ / min) in WKY rats (Quirk et al., 1988). To test this possibility the infusion period was extended to 10 min in the present study. Additionally, we were interested in determining whether autoregulation of $\mathrm{CoBF}$ could be induced by another vasoactive compound, phenylephrine. AII has an influence on vascular resistance through direct action on 
vascular smooth muscle as well as an indirect effect on the central nervous system, resulting in activation of the sympathetic nervous system, and stimulation of vasopressin and catecholamine release (for review see Phillips, 1987). Phenylephrine, on the other hand, is a sympathomimetic drug that elevates blood pressure by increasing heart rate, the heart's conduction and contractility, as well as stimulation of epinephrine and norepinephrine release from the adrenal medulla (for review see Seiden and Dykstra, 1977). These vasoconstrictive compounds are often used for comparison of substances that elevate blood pressure through different modes of action. The results demonstrated that elevations of systemic blood pressure induced by 10 -min infusions of both AII and phenylephrine resulted in an initial increase in CoBF followed by a slow, steady decline toward baseline. Since this response occurred during 5-min infusions of the same dose of AII in SHRs in a previous study (Quirk et al., 1988), the present results are consistent with our interpretation that both WKY rats and SHRs exhibit an autoregulatory response, however, there appears to be a more rapid onset and greater intensity of the response in SHRs.

It is not clear whether there is any physiological significance associated with this strain difference in CoBF. However, it is interesting to note that alterations in $\mathrm{CoBF}$ in SHRs are correlated with times of increased metabolic need, such as the increases in blood pressure that may accompany noise exposure (Wright et al., 1981; Dengerink et al., 1982).

A second major question of the current study addressed the possiblity that the interaction of AII and vascular angiotensin receptors may participate in the regulation of CoBF. During controlled elevations of blood pressure induced by systemic infusions of vasoactive compounds, the typical $\mathrm{CoBF}$ pattern is an initial increase followed by a slow and steady return toward baseline measures. One possible explanation for this pattern is that during large elevations in blood pressure there are increased levels of circulating vasoactive substances. Binding of these compounds to vascular receptors in the supplying vessels of the cochlea may induce vasoconstriction and subsequent decreases in CoBF.
Previous investigations measured significant increases in circulating levels of AII during and following noise exposure in alert rats (Wright et al., 1981). Additionally, investigations utilizing the specific angiotensin-receptor antagonist sarile, have suggested that vascular AII receptors may be involved in the regulation of CoBF (Quirk et al., 1988) Therefore, we chose to locally infuse AII and determine whether changes in CoBF could be induce independent of changes in systemic blood pressure. The results indicate that AICA infusion of AII caused decreases in CoBF in a dose dependent fashion during steady state blood pressure. Infusion of $0.15 \mathrm{M} \mathrm{NaCl}$ resulted in no changes in $\mathrm{CoBF}$ or systemic blood pressure. Furthermore, the decreases in CoBF induced by $\mathrm{AII}$ infusion werc diminished when animals were pretreated with the specific angiotensin-receptor antagonist, sarthran. This supression effect is presumably through competitive occupation of vascular AII receptors. These findings support the participatory role of AII vascular receptors in CoBF autoregulation, are consistent with the finding that AII receptors are present in a number of vascular beds (Shiffrin et al., 1984), and increase the possibility that AII receptors may be found in the vessels supplying the cochlea.

There are a number of limitations concerning the interpretation of the present results. First, preliminary studies demonstrated that local infusions of AII produced elevations in systemic blood pressure if pipette tips with external diameters larger than $20 \mu \mathrm{m}$, or infusion rates greater than or equal to $1 \mu \mathrm{l} / \mathrm{min}$, were utilized. Second, it is clear from the present results that exogenously applied AII can induce vascular vasoconstriction. However, it is probable that other circulating vasoactive hormones and peptides are also involved in CoBF regulation. Finally, the laser Doppler flowmeter provides only a relative measure of CoBF. Laser Doppler measures have, however, been validated against histological measures (Dengerink and Axelsson, 1988), intravital microscopy (LaRouere et al., 1988) and radiotracer clearance (Jung, 1988).

The micropipette infusion system utilized in the current study to infuse into the supplying vesscls of the cochlea appears to be a valuable technique for assessing local regulation of CoBF. Currently, 
studies have been initiated using this technique to infuse other vasoactive hormones and peptides, as well as therapeutic agents. Additionally, measures of red blood cell velocity and vessel diameter changes are now being assessed using intravital microscopy (Nuttall, 1987).

In summary, the results of the current experiment support the interpretation that $\mathrm{CoBF}$ in WKY rats is subject to autoregulation in response to elevations in systemic blood pressure induced by infusion of both AII and phenylepherine. Additionally, decreases in CoBF may be induced by cochlear infusion of AII independent of changes in systemic blood pressure. This AII-induced decrease in CoBF can be inhibited by pretreatment with the competitive angiotensin receptor antagonist, sarthran. These results support the hypothesis that AII binding to vascular receptors induces vasoconstriction of the vessels supplying the cochlea, and therefore may be involved in CoBF autoregulation.

\section{Acknowledgements}

This research was supported by funds provided by the Deafness Research Foundation and Washington State University. We also wish to thank Mr. Bill Ryan of the Washington State University Technical Services Glass Shop for his expert assistance in preparing the glass double $\mathrm{t}$-junctions used in the construction of the flowthrough catheter system. Thanks are also due to Ms. Michelle Griffiths for her excellent editorial assistance.

\section{References}

Baumbach, G. and Heistad, D. (1985) Regional, segmental and temporal heterogeneity of cerebral vascular autoregulation. Ann. Biomed. Eng. 13, 303-310.

Bayliss, W. (1902) On the local actions of the arterial wall to changes in internal pressure. J. Physiol. (Lond) 28, 220-231.

Chang, B., Santillan, G. and Bing, R. (1985) Red cell velocity and autoregulation in the cerebral cortex of the cat brain. Brain Res. 308, 15-24.

Coyle, P. and Heistad, D. (1986) Blood flow through cerebral collateral vessels in hypertensive and normotensive rats. Hypertension (Suppl. II) 8, II67-II71.

Dengerink, H.A., Wright, J.W., Thompson. P. and Dengerink, J.E. (1982) Changes in plasma angiotensin II with noise exposure and their relationship to TTS. J. Acoust. Soc. Am. $72,276-278$.
Dengerink, H., Wright, J., Miller, J. and Goodwin, P. (1985) The effects of nicotine on laser Doppler measures of cochlear blood flow. Hear. Res. 20, 31-36.

Flynn, A., Quirk, W.S., Wright, J.W. and Dengerink, H.A. (1988) A comparison of intracerebroventricularly AII-induced changes in systemic blood pressure and cochlear blood flow in guinea pigs and rats (in preparation).

Goodwin, P., Miller, J., Dengerink, H., Wright, J. and Axelsson, A. (1984) The laser Doppler: A non-invasive measure of cochlear blood flow. Acta Otolaryngol. 98,403-412.

Harper, S. and Bohlen, G. (1981) Microvascular adaptation in the cerebral cortex of adult spontancously hypertensive rats. Hypertension 6, 408-419.

Hultcrantz, E. (1979) The effect of noise on cochlear blood flow in the conscious rabbit. Acta Physiol. Scand. 106, $29-37$.

Hultcrantz, E., Hillerdal, M. and Angelborg, C. (1982). Effect of nicotinic acid on cochlear blood flow. Acta Otorhinolaryngol. 234, 151-155.

Jung, W.K., Kraus, M. and Schon. F.J. (1988) Inner ear studies by combination of laser Doppler anemetrt and radioclearance techniques (in press).

LaRouere, M.J., Sillman, J.S., Nuttall, A.L. and Miller, J.M. (1988) A comparison of laser Doppler and intravital microscopy measures of cochlear. blood flow. Otolaryngol. Head-Neck Surg. (in press).

Laugel, G.R., Dengerink, H.A. and Wright, J.W. (1988) Ovarian steriod and vasoconstrictor effects on cochlear blood flow. Hear. Res. 31, 245-252.

Lawrence, M., Nuttall, A.L. and Burgio, P.A. (1977) Oxygen reserve and autoregulation in the cochlea. Acta Otolaryngol. 83, 146-152.

Miller, J.M., Goodwin, P.C. and Marks, N.J. (1984) Inner ear blood flow measured with a laser Doppler system. Arch Otolaryngol. 110, 305-308.

Miller, J.M., Marks, N.J. and Goodwin P. C. (1983) Laser Doppler measurements of cochlear blood flow. Hear. Res. 11, 385-394.

Nuttall, A.L. (1987) Velocity of red blood cell flow in the capillaries of the guinea pig cochlea. Hear. Res. 27, 121-128.

Pasternak, J.F. and Groothius, D.R. (1985) Autoregulation of cerebral blood flow in the newborn beagle puppy. Biol. Neonate $48,100-109$.

Phillips, M.I. (1983) New evidence for brain angiotensin and for its role in hypertension. Fed. Proc. 42, 2667-2672.

Phillips, M.I. (1987) Functions of angiotensin in the central nervous system. Ann. Rev. Physiol. 49, 413-435.

Quirk, W.S., Wright, J.W., Dengerink, H.A. and Miller, J.M. (1988) Angiotensin II-induced changes in cochlear blood flow and blood pressure in normotensive and spontaneously hypertensive rats. Hear. Res. 32, 129-136.

Ramsey, D. (1982) Effects of circulating angiotensin II on the brain. In: W.F. Ganong and L. Martini (Eds.), Frontiers in Neuroendocrinology (vol. 7), Raven Press, New York.

Reid, I.A. (1979) The brain-renin angiotensin system: A critical analysis. Fed. Proc. 38, 2255-2259.

Sadoshima, S., Busija, D. and Heistad, D. (1985) Mechanisms of protection against stroke in stroke-prone spontaneously hypertensive rats. Am. J. Physiol. 244, H406-H412. 
Shiffrin, E.L., Thome, F.S. and Genest, J. (1984) Vascular angiotensin II receptors in SHR. Hypertension 6, 682-688.

Sillman, J.S., LaRouere, M.J., Nuttall, A.L. and Lawrence, M. (1988) Recent advances in cochlear blood flow measurements. Ann. Otol. Rhinol. Laryngol. Trans. Am. Otol. Soc. $97,1-8,1988$.

Snow, J.B. and Suga, F. (1972) Control of cochlear blood flow. In: A.J.D. DeLorenzo (Ed.), Vascular disorders and hearing defects, University Park, Baltimore, U.S.A. pp. 167-183.

Suga, F. and Snow, J. B. (1969) Adrenergic control of cochlear blood flow. Ann. Otol. Rhino. Laryngol. 78, 358-360.

Strangaard, S., Jones, J.V., Mackenzie, E.T. and Harper, A.M. (1975) Upper limit of cerebral blood flow autoregulation in experimental renovascular hypertension in the baboon. Circ. Res. 46, 37-47.

Wright, J.W., Dengerink, H.A., Thompson, P. and Morseth, S. (1981) Plasma angiotensin II changes with noise exposure at three levels of ambient temperature. J. Acoust. Soc. Am. $70,1353-1356$

Wright, J.W., Dengerink, H.A., Miller, J.M. and Goodwin, P.C. (1985a) Potential role of angiotensin II in noise-induced increases in inner ear blood flow. Hear. Res. 17. $41-46$.

Wright, J. W., Morseth, S. L., Abhold, R. H. and Harding, J.W. (1985b) Pressor action and dipsogenicity induced by angiotensin II and III in rats. Am. J. Physiol. 249, R514-R521.

Wright, J.W. and Harding, J.W. (1988) A re-evaluation of angiotensin II's potency as a pressor and dipsogenic agent in normotensive and hypertensive animal models. In: J.W. Harding, J.W., Wright, R.C. Speth, and C.D. Barnes (Eds.), Angiotensin and Blood Pressure Regulation, Academic Press, San Diego, pp. 209-238. 